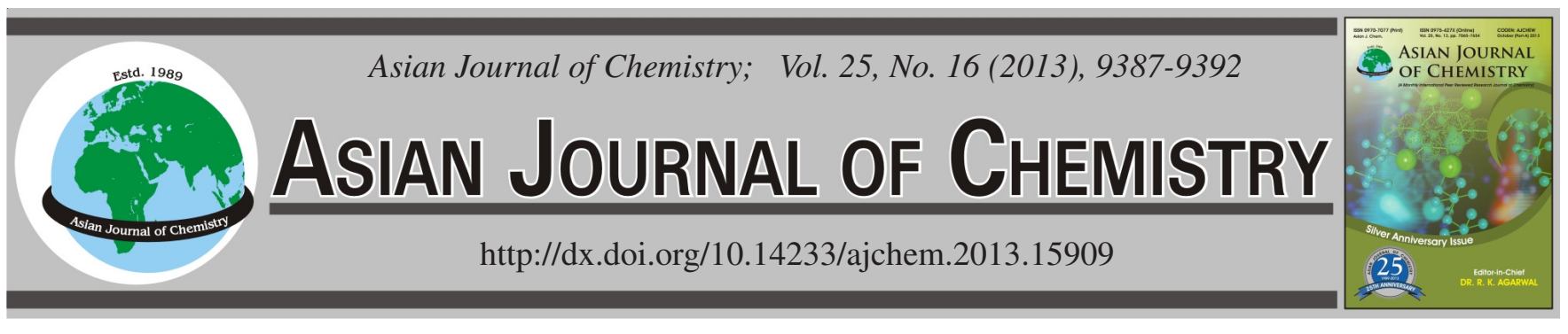

\title{
Effect of Photocatalytic Treatments on Physical and Biological Properties of Textile Dyeing Wastewater
}

\author{
FALAH H. HuSSEIN
}

Department of Chemistry, College of Science, Babylon University, Hilla, Iraq

Corresponding author: E-mail: abohasan_hilla@yahoo.com

\begin{abstract}
The main objective of this research was to observe and evaluate the photocatalytic treatability of textile industrial wastewater to reuse it again for different purposes such as agricultural irrigation, recreational uses, groundwater recharge, industrial reuse, environmental uses, non-potable urban uses, indirect potable reuse and direct potable reuse. The heterogeneous photocatalytic degradation of real and another four prepared simulated textile industrial wastewater (Vat yellow, Reactive black, Reactive blue and Cowboy dyes were carried out on a laboratory scale using three commercial photocatalysts namely, anatase, rutile and zinc oxide. Comparison between the efficiency of the three photocatalysts indicated that their efficiency followed the decreasing order of $\mathrm{ZnO}>\mathrm{TiO}_{2}($ anatase $)>\mathrm{TiO}_{2}$ (rutile). However, the amount of zinc oxide required to reach the optimum activity is two times more than that for titanium dioxide (anatase or rutile) and the sequence was changed in the favor of anatase when the same concentration of mass was used $\left(175 \mathrm{mg} \mathrm{L}^{-1}\right)$. Photocatalytic treatments carried out over a suspension of titanium dioxide (anatase or rutile) or zinc oxide under artificial irradiation. The progress of treatment stages was followed by using different techniques of analysis. Water quality, physical and microbiological parameters for untreated and treated industrial wastewater were determined using different techniques. The physical parameters include colour, temperature $\left({ }^{\circ} \mathrm{C}\right)$, turbidity/NTU, electrical conductivity $\left(\mu\right.$ mohs $\left.\mathrm{cm}^{-1}\right)$, total suspended solids $(\mathrm{ppm})$ and total dissolved solids (ppm). Under optimal conditions, the extent of decolorization was $100 \%$ after 42, 35, 10, 12 and 17 min of irradiation for real industrial wastewater and prepared simulated textile industrial wastewater (Vat yellow, Reactive black, Reactive blue and Cowboy dyes), respectively, when titanium dioxide (anatase) was used. The time for complete decolorization for real and simulated Vat yellow, Reactive black and Reactive blue dyes was found longer when rutile was used (370, 300, 120 and $90 \mathrm{~min}$ ). However, simulated Cowboy dye did not decolorized completely even when the time of irradiation was increased to $400 \mathrm{~min}$ when rutile was used as photocatalyst. When zinc oxide was used the extent of decolorization was $100 \%$ after shorter time compared with that needed when anatase and rutile were used (30, 20, 7, 5 and 12 min for the real and simulated textile wastewater dyes, respectively). The temperature of real industrial wastewater was $40^{\circ} \mathrm{C}$ at the collection point while for simulated samples was about $25^{\circ} \mathrm{C}$. The temperature of all treated textile wastewater dyes was about $30{ }^{\circ} \mathrm{C}$ at the end of irradiation time of each textile wastewater dyes. It was observed that turbidity was reduced from 820 to 4.68 NTU for the real textile wastewater dyes (more than $99 \%$ ) when $\mathrm{ZnO}$ used for treatment and for simulated textile wastewater dyes turbidity was removed by $92-$ $98 \%$. After treatment with anatase, rutile and zinc oxide, the electrical conductivity of real and simulated textile wastewater dyes was found to decrease up to 14-92, 20-68 and 29-80\%, respectively. Total suspended solids and total dissolved solids values for real and simulated textile industrial wastewater fell within the range 4-6350 and 10-7820 ppm, respectively before treatment. Total suspended solids and total dissolved solids values were removed after photocatalytic treatments by $92.86-100$ and $75-98.90 \%$, respectively.
\end{abstract}

Key Words: Photocatalytic treatment, Textile dyeing wastewater.

\section{INTRODUCTION}

The textile effluents contain more than $15 \%$ of the total world production of dyes where 10,000 pigments or dyes are used in this type of industry. Most of them are toxic substances to human and aquatic life ${ }^{1,2}$. Pereira et al. ${ }^{3}$ and Najafi et al. ${ }^{4}$, reported that treatment of industrial wastewater prior to reusing it for agricultural and landscape irrigation is an important step for reduction of environmental and health risks. Due to the scarcity of fresh water resources around our region, effluents from wastewater treatment plants has increasingly been reclaimed and reused. In some arid and semi-arid regions reclaimed water has been recognized as a valuable resource $^{5}$. United Nation ${ }^{6}$, reported at 2003 that 2.7 billion people will face water scarcity by 2025 and the Arab world is dominated by water scarcity ${ }^{7}$. More than 50 million people lack access to safe drinking water in the Arab world.

Arab water council in a recent report $^{8}$ explained that solutions to water scarcity problems require the consideration of cultural, educational, communication and scientific aspects. 
The report concentrated on the importance of reusing of treated water. As the quantity of treated wastewater is an important issue, the quality of the treated water should be taken in consideration, especially with respect to the impact of wastewater reuse on public health i.e., reuse of the treated industrial wastewater must ensure that public health is maintained.

Results presented in our previous study which also supported by Arab Science and Technology Foundation indicated that visible light (solar or artificial light)/ZnO and visible light (solar or artificial light)/ $/ \mathrm{TiO}_{2}$ systems could be efficiently used for the treatments textile industrial wastewater ${ }^{9,10}$. The results indicated that the used technique is an efficient technique for the treatments of industrial wastewater through a photocatalytic process and the transformation is practically complete in a reasonable irradiation time.

The popularity of titanium dioxide as a photocatalyst is based on its non-environmental impact, low cost, high stability, high natural abundance and versatile potential applications $^{11-21}$.

Two methods have been mostly applied for using titanium dioxide in photocatalytic degradation processes namely, suspension in aqueous medium and immobilization on suitable support material. Although the suspension in aqueous medium systems always gives higher photocatalytic degradation efficiencies the reactor must be equipped with a liquid-solid separator to remove the fine suspended particles. Moreover, turbidity in the downstream due to the existence of fine particles is undesirable. In view of above mentioned points, immobilization of photocatalyst seems to be more suitable for using in photocatalytic degradation processes ${ }^{22-24}$.

It is well known that anatase is a photoactive phase, while rutile is a low active or inactive photocatalysts. The photoactivity is mainly influenced by crystal structure, crystallite size, surface area, porosity, surface acidity, surface water content and adsorbed hydroxyl groups ${ }^{25-27}$. Decolorization percentage of real textile industrial wastewater on rutile, anatase and zinc oxide shows that $\mathrm{ZnO}$ is the most active ${ }^{28}$. $\mathrm{ZnO}$ is more active than $\mathrm{TiO}_{2}$ due to the absorption of wider spectrum light ${ }^{29}$. However, the amount of zinc oxide required to reach the optimum activity is two times more than that for titanium dioxide (anatase or rutile) ${ }^{28}$. In another study, Hussein et $a l .{ }^{30}$ observed that $\mathrm{ZnO}$ is less active than anatase when the same weight of catalysts is used for photocatalytic degradation of textile wastewater. Akyol et al. ${ }^{31}$, reported that $\mathrm{ZnO}$ is more active than $\mathrm{TiO}_{2}$ for the decolorization efficiency of aqueous solution of a commercial textile dye due to the band gap energy, the charge carrier density and the crystal structure. Decolorization efficiency of real textile industrial wastewater in the presence and absence of catalyst and/or solar radiation was also investigated ${ }^{10}$. The results indicate also that that $\mathrm{ZnO}$ is the most active. Kalra et al. ${ }^{18}$, reported that advanced oxidation processes are better treatment options than the conventional treatment methods commonly adopted in wastewater treatment plants.

The most important physical characteristics of industrial wastewater included, temperature $/{ }^{\circ} \mathrm{C}(\mathrm{T})$, turbidity/NTU (TD), electrical conductivity/ $\mu$ mohs $\mathrm{cm}^{-1}$ (EC), total suspended solids/ ppm (TSS) and total dissolved solids/ppm (TDS). Textile industry wastewater is characterized by highly visible colour and high value of BOD, COD and alkaline $\mathrm{pH}(9-11)^{32,33}$.

The aim of the present project is to investigate photocatalytic treatments of real and simulated textile wastewater using $\mathrm{TiO}_{2}$ and $\mathrm{ZnO}$ as photocatalysts with irradiation with artificial source of radiation and to evaluate the properties of treated of textile industrial wastewater to reuse it again for different purposes.

\section{EXPERIMENTAL}

Artificial photocatalytic reactor: Artificial irradiation experiments are performed in a homemade reactor. The reactor consists of graduated $1000 \mathrm{~mL}$ Pyrex glass beaker and a magnetic stirring setup. The radiation source was a Mazdan $400 \mathrm{~W}$ high pressure mercury lamp (Germany). The lamp was positioned perpendicularly above the reaction vessel.

All chemicals used for analysis in this study were analytical grade, supplied by BDH in a high purity $(\geq 99.9)$ and were used as supplied.TiO $\mathrm{T}_{2} \mathrm{P}-25$ anatase purchased from Degussa, $\mathrm{TiO}_{2}$ rutile was obtained from Fluka and zinc oxide with $99.5 \%$ purity, supplied by Carlo ERBA.Real textile industrial wastewater dyes were collected at the mid of October 2010 from Textile Factory in Baghdad (Al- Kademeia). Samples of simulated dyes (Vat yellow, Reactive black and Reactive blue) were supplied from the same factory while Cowboy dye was supplied by Al-Karama private factory in Baghdad.

Reaction procedure: In all experiments $700 \mathrm{mg}$ of the catalyst, titanium dioxide (anatase or rutile) or $1400 \mathrm{mg}$ of zinc oxide, was suspended in $400 \mathrm{~mL}$ of industrial wastewater solution using a magnetic stirrer. In a set of experiments which used for comparison the catalytic activity $700 \mathrm{mg}$ of each single catalyst was taken and suspended in $400 \mathrm{~mL}$ of the industrial wastewater.

Dye concentration used was $50 \mathrm{ppm}$ for all simulated textile wastewater dyes, while the concentration of real industrial wastewater was used as supplied. Concentration of the textile wastewater dyes were measured at the wavelength of the maximum absorbance $\left(\lambda_{\max }\right)$, which was determined using a UV-visible spectrophotometer. The percentage removal of a dye was calculated from the absorbance of the supernatant to the standard curve of each dye obtained from its concentration. The wavelength of the maximum absorbance $\left(\lambda_{\max }\right)$ of the real and the four simulated industrial wastewater dyes used in this project is $304,420,570,666$ and $572 \mathrm{~nm}$, respectively.

Physical characterization of industrial wastewater: The photocatalytic decolorization of collected textile wastewater dyes of real and four simulated textile industrial wastewater was examined under artificial source of irradiation using titanium dioxide (anatase or rutile or zinc oxide). The progress of decolorization was followed spectrophotometrically at different intervals of time.

When the colour of the wastewater completely disappeared, the irradiation source switched off, the treated wastewater centrifuged (4,000 rpm, $15 \mathrm{~min}$ ) in an $800 \mathrm{~B}$ centrifuge. The supernatant was carefully removed by a syringe with a long pliable needle and centrifuged again at same speed and for the same period of time. This second centrifugation was 
found necessary to remove fine particles of $\mathrm{TiO}_{2}$ or $\mathrm{ZnO}$. After the second centrifugation, apart of the treated textile wastewater dyes was used to measure other physical properties using standard procedures. Temperature was measured using portable calibrated mercury thermometer at the collection point for untreated real textile wastewater dyes and after preparation for the four simulated textile wastewater dyes ${ }^{40}$. The temperature was also measured for all treated textile wastewater dyes at the end of each experiment. Turbidity, electrical conductivity (EC) and total dissolved solid (TDS) were determined in situ electronically with appropriate meters. Total suspended solids (TSS) were determined by filtering a known amount of textile wastewater dyes through a pre-weighed filter paper. The filter paper was then dried at $105^{\circ} \mathrm{C}$.

\section{RESULTS AND DISCUSSION}

Physical characterization of industrial wastewater: Table-1 summarizes the physical parameters which were measured for real and four types of simulated textile industrial wastewater at the beginning to characterize the wastewater.

Temperature of collected real textile wastewater dyes was $40^{\circ} \mathrm{C}$, while the temperature of the four simulated textile wastewater dyes after preparation was $25^{\circ} \mathrm{C}$.

Turbidity, which indicates the salinity of water, was found to be 820.00 N.T.U. and within the ranges (2.04-266.00 N.T.U.) for the simulated textile wastewater dyes.

Conductivity which reflects the total amount of salt in water $\left(\mathrm{Ca}^{2+}, \mathrm{Mg}^{2+}, \mathrm{Na}^{+}, \mathrm{K}^{+}, \mathrm{CO}_{3}{ }^{2-}, \mathrm{SO}_{4}{ }^{2-}\right)$ and it is used to determine the salinity of water was found very high in the real textile wastewater $\left(5610 \mu \mathrm{mohs} \mathrm{cm}^{-1}\right)$ compared with simulated textile wastewater dyes ( $\left.35-110 \mu \mathrm{mohs} \mathrm{cm}^{-1}\right)$.

The results of analysis of total suspended solids (TSS) in the real textile wastewater was found $6350 \mathrm{ppm}$ and in the range 4-28 ppm for the simulated textile wastewater dyes.
Total dissolved solids (TDS) for real was very high (7820 ppm) compared with the value for the simulated four textile wastewater dyes (10-70 ppm).

Photocatalytic degradation of industrial wastewater using titanium dioxide (anatase): The decolorization efficiencies differ with the difference in type of dye used in textile industry.

Under optimal conditions, the extent of decolorization was $100 \%$ after 42 min of irradiation for real textile industrial wastewater and between 10 and 35 min for prepared simulated industrial wastewater.

The results (Table-2) show that the photocatalytic treatments using anatase improved the physical properties of the treated textile wastewater.

The temperature of all treated textile wastewater dyes was found $30 \pm 2{ }^{\circ} \mathrm{C}$. The temperature at the collection point of real textile wastewater was higher than that after treatment.

The removing percentage of turbidity reached for real textile industrial wastewater dyes 99, 99, 100, 98 and $94 \%$ for simulated textile wastewater dyes Vat yellow, Reactive black, Reactive blue and Cowboy, respectively.

The electrical conductivity (EC) of real textile wastewater dyes before and after treatment is given in Table-2. It was 5610 $\mu \mathrm{mohs} \mathrm{cm}^{-1}$, which is very high and indicates high level of pollution. However it was reduced to $437 \mu$ mohs $\mathrm{cm}^{-1}$ after treatment. The reduction of electrical conductivity was 14, 28, 71 and $49 \%$ for simulated textile wastewater dyes Vat yellow, Reactive black, Reactive blue and Cowboy, respectively.

The results in Table-2 also indicate that total suspended solids (TSS) and total dissolved solids (TDS) values for treated real and simulated textile industrial wastewater dyes were reduced 92-100 and 75-99\%, respectively.

Photocatalytic degradation of industrial wastewater using titanium dioxide (rutile): Under optimal conditions,

\begin{tabular}{|c|c|c|c|c|c|c|c|c|c|c|}
\hline \multicolumn{11}{|c|}{$\begin{array}{c}\text { TABLE-1 } \\
\text { CHARACTERISTICS OF REAL AND SIMULATED TEXTILE } \\
\end{array}$} \\
\hline \multirow{2}{*}{\multicolumn{2}{|c|}{ Parameter }} & \multicolumn{9}{|c|}{ Type of textile wastewater } \\
\hline & & Real & \multicolumn{2}{|c|}{ Simulated Vat yellow } & \multicolumn{2}{|c|}{ Simulated Reactive black } & \multicolumn{2}{|c|}{ Simulated Reactive blue } & \multicolumn{2}{|c|}{ Simulated Cowboy } \\
\hline \multicolumn{2}{|l|}{ Color } & Yellow & \multicolumn{2}{|c|}{ Vat yellow } & \multicolumn{2}{|c|}{ Reactive black } & \multicolumn{2}{|c|}{ Reactive blue } & \multicolumn{2}{|c|}{ Cowboy } \\
\hline \multicolumn{2}{|l|}{ Temperature $\left({ }^{\circ} \mathrm{C}\right)$} & 40 & \multicolumn{2}{|l|}{25} & \multicolumn{2}{|c|}{25} & \multicolumn{2}{|c|}{25} & \multicolumn{2}{|c|}{25} \\
\hline \multicolumn{2}{|l|}{ Turbidity/NTU } & 820.00 & \multicolumn{2}{|l|}{266.00} & \multicolumn{2}{|c|}{2.04} & \multicolumn{2}{|c|}{57.00} & \multicolumn{2}{|c|}{19.47} \\
\hline \multicolumn{2}{|c|}{ Conductivity $\left(\mu \mathrm{mohs} \mathrm{cm}^{-1}\right)$} & 5610 & \multicolumn{2}{|l|}{35} & \multicolumn{2}{|c|}{141} & \multicolumn{2}{|c|}{110} & \multicolumn{2}{|c|}{83} \\
\hline Total suspended so & s (ppm) & 6350 & \multicolumn{2}{|l|}{4} & \multicolumn{2}{|c|}{19} & \multicolumn{2}{|c|}{28} & \multicolumn{2}{|c|}{22} \\
\hline \multicolumn{2}{|c|}{ Total dissolved solids (ppm) } & 7820 & \multicolumn{2}{|l|}{10} & \multicolumn{2}{|c|}{70} & & 50 & & 40 \\
\hline & & PHYSICAL & PROPERTIE & $\begin{array}{r}\text { TA } \\
\text { OF TREA } \\
\end{array}$ & $\begin{array}{l}\text { BLE-2 } \\
\text { TED WAST }\end{array}$ & WATER W & TH ANATA & & & \\
\hline & & & & & Type of text & e wastewate & & & & \\
\hline Parameter & & eal & $\begin{array}{l}\text { Simu } \\
\text { Vat y }\end{array}$ & $\begin{array}{l}\text { ated } \\
\text { llow }\end{array}$ & $\begin{array}{r}\text { Sim } \\
\text { Reacti }\end{array}$ & $\begin{array}{l}\text { lated } \\
\text { e black }\end{array}$ & $\begin{array}{r}\text { Simu } \\
\text { Reacti }\end{array}$ & $\begin{array}{l}\text { ated } \\
\text { e blue }\end{array}$ & $\mathrm{Sim}$ & $\begin{array}{l}\text { lated } \\
\text { boy }\end{array}$ \\
\hline & Untreated & Treated & Untreated & Treated & Untreated & Treated & Untreated & Treated & Untreated & Treated \\
\hline Color & Yellow & Colorless & $\begin{array}{l}\text { Vat } \\
\text { yellow }\end{array}$ & Colorless & $\begin{array}{l}\text { Reactive } \\
\text { black }\end{array}$ & Colorless & $\begin{array}{l}\text { Reactive } \\
\text { blue }\end{array}$ & Colorless & Cowboy & Colorless \\
\hline Temperature $\left({ }^{\circ} \mathrm{C}\right)$ & 40 & 30 & 25 & 31 & 25 & 29 & 25 & 32 & 22 & 28 \\
\hline Turbidity (NTU) & 820.00 & 5.76 & 266.00 & 2.55 & 2.040 & ND & 57.00 & 1.08 & 19.47 & 1.01 \\
\hline $\begin{array}{l}\text { Conductivity } \\
\left(\mu \mathrm{mohs} \mathrm{cm}^{-1}\right)\end{array}$ & 5610 & 437 & 35 & 30 & 141 & 102 & 110 & 32 & 83 & 42 \\
\hline $\begin{array}{l}\text { Total suspended } \\
\text { solids (ppm) }\end{array}$ & 6350 & 18 & 4 & ND & 19 & 1 & 28 & 2 & 22 & 1 \\
\hline $\begin{array}{l}\text { Total dissolved } \\
\text { solids ( } \mathrm{ppm})\end{array}$ & 7820 & 86 & 10 & 1 & 70 & 4 & 50 & 3 & 40 & 3 \\
\hline
\end{tabular}


the extent of decolorization was $100 \%$ after 370, 300, 120 and $90 \mathrm{~min}$ of irradiation for real industrial wastewater and prepared simulated textile industrial wastewater which are Vat yellow, Reactive black and Reactive blue respectively, when titanium dioxide (rutile) was used as photocatalyst. However, simulated 4 (Cowboy dyes) did not decolourized completely even when the time of irradiation was increased to $400 \mathrm{~min}$.

The results (Table-3) show that the photocatalytic treatments using rutile improved the physical properties of the treated textile wastewater.

The temperature of all treated dyes was found $30 \pm 2{ }^{\circ} \mathrm{C}$. The temperature at the collection point of real textile wastewater was higher than that after treatment $\left(40^{\circ} \mathrm{C}\right)$.

The removing percentage of turbidity reached for real textile industrial wastewater dyes $88,92,100,91$ and $71 \%$ for simulated textile wastewater dyes Vat yellow, Reactive black, Reactive blue and Cowboy, respectively.

The electrical conductivity (EC) of real textile wastewater dye before and after treatment is given in Table-3. It was 5610 $\mu$ mohs $\mathrm{cm}^{-1}$, which is very high and indicates high level of pollution. However it was reduced by $88 \%$ after treatment with rutile. The reduction of electrical conductivity in simulated textile wastewater dyes was $11,57,41$ and $18 \%$ for simulated textile wastewater dyes Vat yellow, Reactive black, Reactive blue and Cowboy, respectively.

The results indicate that after treatment of real and simulated textile industrial wastewater the decrease in total suspended solids (TSS) and total dissolved solids (TDS) levels were found to be in the range of 82-100 and 80-99\%, respectively.
Photocatalytic degradationof industrial wastewater using zinc oxide: Complete decolorization of textile industrial wastewater was obtained after 20, 7, 5 and $12 \mathrm{~min}$ of irradiation for prepared simulated textile industrial wastewater (Vat yellow, Reactive black, Reactive blue and Cowboy dyes, respectively) and after $0.5 \mathrm{~h}$ for real industrial wastewater. These results were obtained when the concentration of zinc oxide was $350 \mathrm{mg} \mathrm{L}^{-1}$.

The results (Table-4) show that the photocatalytic treatments using zinc oxide improved the physical properties of the treated textile wastewater.

The temperature of all treated textile wastewater dyes was found $30 \pm 2{ }^{\circ} \mathrm{C}$. The temperature at the collection point of real textile wastewater was higher than that after treatment.

The turbidity of textile wastewater dyes used in this study was found to be in the range of 2.040-820.00 and ND-4.88 NTU before and after treatment, respectively.

The electrical conductivity (EC) of real textile wastewater dyes before and after treatment is given in Table-4. It was 5610 $\mu$ mohs $\mathrm{cm}^{-1}$, which is very high and indicates high level of

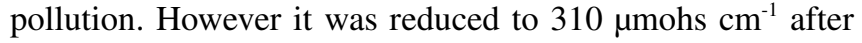
treatment. The reduction of electrical conductivity was 95, 9, 14, 75 and $40 \%$ for real and simulated Vat yellow, Reactive black, Reactive blue and Cowboy dyes, respectively.

The results in Table-4 also indicate that total suspended solids (TSS) and total dissolved solids (TDS) values for treated real and simulated textile industrial wastewater dyes were reduced to 100 and $99-100 \%$, respectively.

TABLE-3

PHYSICAL PROPERTIES OF TREATED WASTEWATER WITH RUTILE

\begin{tabular}{|c|c|c|c|c|c|c|c|c|c|c|}
\hline \multirow{3}{*}{ Parameter } & \multicolumn{10}{|c|}{ Type of textile wastewater } \\
\hline & \multicolumn{2}{|c|}{ Real } & \multicolumn{2}{|c|}{$\begin{array}{c}\text { Simulated } \\
\text { Vat yellow }\end{array}$} & \multicolumn{2}{|c|}{$\begin{array}{c}\text { Simulated } \\
\text { Reactive black }\end{array}$} & \multicolumn{2}{|c|}{$\begin{array}{c}\text { Simulated } \\
\text { Reactive blue }\end{array}$} & \multicolumn{2}{|c|}{$\begin{array}{c}\text { Simulated } \\
\text { Cowboy }\end{array}$} \\
\hline & Untreated & Treated & Untreated & Treated & Untreated & Treated & Untreated & Treated & Untreated & Treated \\
\hline Color & Yellow & Colorless & $\begin{array}{c}\text { Vat } \\
\text { yellow }\end{array}$ & Colorless & $\begin{array}{c}\text { Reactive } \\
\text { black }\end{array}$ & Colorless & $\begin{array}{l}\text { Reactive } \\
\text { blue }\end{array}$ & Colorless & Cowboy & $\begin{array}{l}\text { Pale } \\
\text { blue }\end{array}$ \\
\hline Temperature $\left({ }^{\circ} \mathrm{C}\right)$ & 40 & 30 & 25 & 29 & 25 & 28 & 25 & 30 & 20 & 32 \\
\hline Turbidity (NTU) & 820.00 & 98.40 & 266.00 & 21.28 & 2.040 & ND & 57.00 & 5.18 & 19.47 & 5.56 \\
\hline $\begin{array}{l}\text { Conductivity ( } \mu \\
\text { mohs } \mathrm{cm}^{-1} \text { ) }\end{array}$ & 5610 & 678 & 35 & 31 & 141 & 80 & 110 & 65 & 83 & 68 \\
\hline $\begin{array}{l}\text { Total suspended } \\
\text { solids (ppm) }\end{array}$ & 6350 & 76 & 4 & ND & 19 & 2 & 28 & 3 & 22 & 4 \\
\hline $\begin{array}{l}\text { Total dissolved } \\
\text { solids (ppm) }\end{array}$ & 7820 & 104 & 10 & 2 & 70 & 4 & 50 & 5 & 40 & 8 \\
\hline
\end{tabular}

TABLE-4

CHARACTERISTICS (PHYSICAL PARAMETERS) OF REAL AND SIMULATED TEXTILE WASTEWATER AFTER TREATMENTS WITH ZINC OXIDE

\begin{tabular}{|c|c|c|c|c|c|c|c|c|c|c|}
\hline \multirow{3}{*}{ Parameter } & \multicolumn{10}{|c|}{ Type of textile wastewater } \\
\hline & \multicolumn{2}{|c|}{ Real } & \multicolumn{2}{|c|}{$\begin{array}{l}\text { Simulated } \\
\text { Vat yellow }\end{array}$} & \multicolumn{2}{|c|}{$\begin{array}{c}\text { Simulated } \\
\text { Reactive black }\end{array}$} & \multicolumn{2}{|c|}{$\begin{array}{c}\text { Simulated } \\
\text { Reactive blue }\end{array}$} & \multicolumn{2}{|c|}{$\begin{array}{l}\text { Simulated } \\
\text { Cowboy }\end{array}$} \\
\hline & Untreated & Treated & Untreated & Treated & Untreated & Treated & Untreated & Treated & Untreated & Treated \\
\hline Color & Yellow & Colorless & $\begin{array}{c}\text { Vat } \\
\text { yellow }\end{array}$ & Colorless & $\begin{array}{c}\text { Reactive } \\
\text { black }\end{array}$ & Colorless & $\begin{array}{l}\text { Reactive } \\
\text { blue }\end{array}$ & Colorless & Cowboy & Colorless \\
\hline Temperature $\left({ }^{\circ} \mathrm{C}\right)$ & 40 & 30 & 25 & 30 & 25 & 28 & 25 & 30 & 20 & 31 \\
\hline Turbidity (NTU) & 820.00 & 4.88 & 266.00 & 1.86 & 2.040 & ND & 57.00 & ND & 19.47 & ND \\
\hline 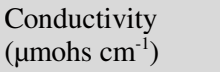 & 5610 & 310 & 35 & 32 & 141 & 121 & 110 & 28 & 83 & 50 \\
\hline $\begin{array}{l}\text { Total suspended } \\
\text { solids (ppm) }\end{array}$ & 6.350 & 6 & 4 & ND & 19 & ND & 28 & ND & 22 & ND \\
\hline $\begin{array}{l}\text { Total dissolved } \\
\text { solids (ppm) }\end{array}$ & 7820 & 63 & 10 & ND & 70 & ND & 50 & ND & 40 & ND \\
\hline
\end{tabular}


Biological characterization of treated industrial wastewater: Fig. 1 shows the total viable count of total colony forming units (CFUs) in the real textile industrial wastewater dye before and after treatment with the existence of $\mathrm{ZnO}$ as photocatalyst. The CFUs value was $285 \mathrm{CFU} / \mathrm{mL}$ and after $0.5 \mathrm{~h}$ of irradiation it was reduced to $4 \mathrm{CFU} / \mathrm{mL}$ ( $>98 \%$ removal).

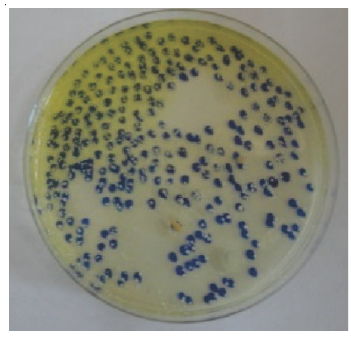

A

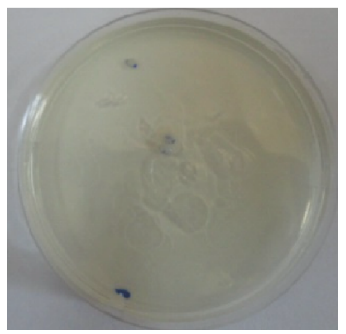

B
Fig. 1. Biological characterization of real textile industrial wastewater A-before treatment, B-after treatment

The present study revealed that all photocatalysts were successful in improving the physical and biological properties of industrial wastewater. However, different photocatalysts gave different activities.

Effect of type of catalyst on decolorization percentages of real and simulated dyes: Fig. 2 shows the changes the colour of real and simulated textile industrial wastewater by using different types of catalysts. It is clear from these figures that zinc oxide is the most effective catalyst and with all types of dyes the extent of decolorization reaches $100 \%$. The extent
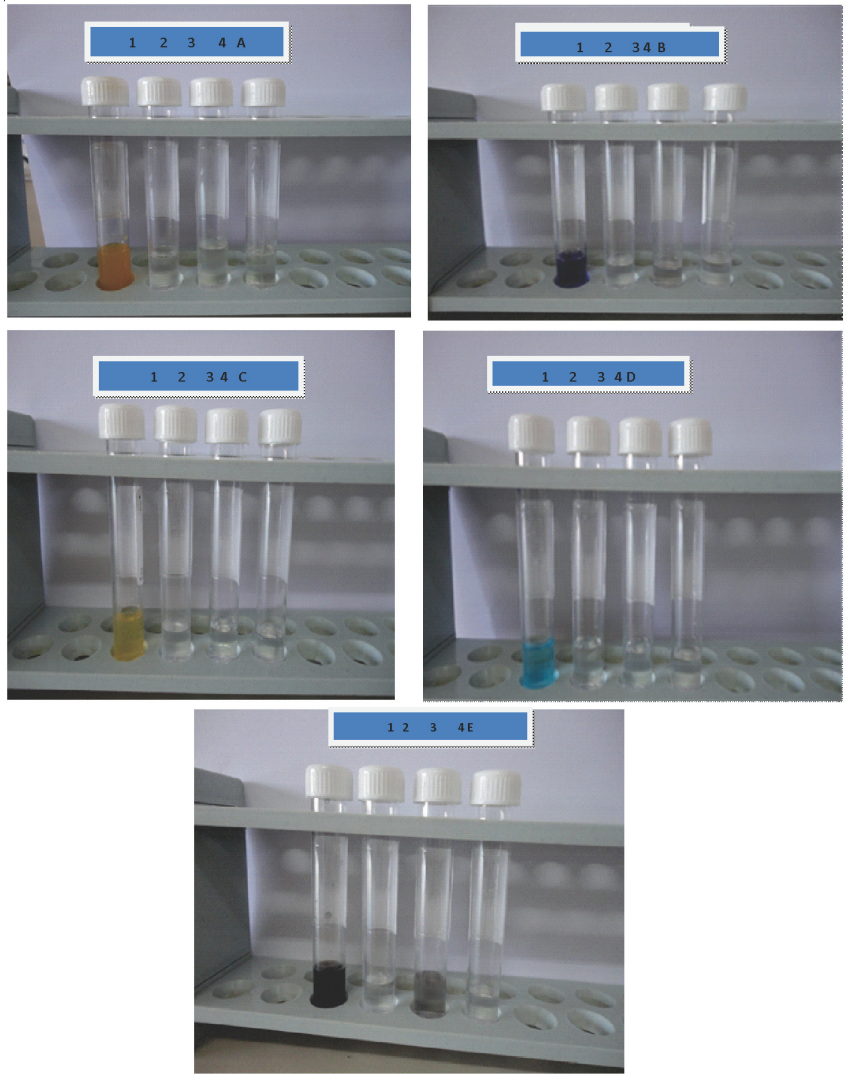

Fig. 2. Dye colour 1-before treatment 2-after treatment with anatase 3after treatment with rutile 4- after treatment with $\mathrm{ZnO}$ ( A-Real dye B-Vat yellow, C-Reactive black, D-Reactive blue, E- Cowboy dyes) of decolorization was also $100 \%$ when anatase was used as photocatalyst but that needed more time than that needed when zinc oxide was used.However when rutile was used as photocatalyst, the time needed for complete decolorization was very long compared with anatase and zinc oxide. The extent of decolorization was $100 \%$ after 370, 300, 120 and 90 min of irradiation for real industrial wastewater and prepared simulated textile industrial wastewater which are Vat yellow, Reactive black and Reactive blue respectively, when titanium dioxide (rutile) was used as photocatalyst. However, simulated Cowboy dyes did not decolorized completely even when the time of irradiation was increased to $400 \mathrm{~min}$.

The results indicated that the activity of different catalysts fell in the sequence:

$$
\mathrm{ZnO}>\mathrm{TiO}_{2} \text { (Anatase) }>\mathrm{TiO}_{2} \text { (Rutile) }
$$

This sequence was obtained when the optimum concentration of each catalyst was used $\left(1.750 \mathrm{~g} \mathrm{~L}^{-1}\right.$ of anatase or rutile and $3.50 \mathrm{~g} \mathrm{~L}^{-1}$ of zinc oxide). When equal concentration of catalyst was used $\left(1.750 \mathrm{~g} \mathrm{~L}^{-1}\right)$, the sequence was changed to:

$$
\mathrm{TiO}_{2}(\text { Anatase })>\mathrm{ZnO}>\mathrm{TiO}_{2}(\text { Rutile })
$$

These findings are in good agreement with that reported before ${ }^{37}$.

\section{Conclusion}

- Textile effluents are highly polluted and must be treated properly before discharging into the drainage channel to minimize the effect of various pollutants on the environment.

- Photocatalytic oxidation technique shows to be promising methods for treatments aimed at reuse of textile wastewaters, resulting in direct environmental and economic benefits.

- This technique can be used to remove colour and other physical and biological properties to an extent which is sufficient for water reusing for agricultural and domestic purposes.

\section{ACKNOWLEDGEMENTS}

The author gratefully acknowledged the financial support provided by Arab Science and Technology Foundation (ASTF). Sincere appreciation to all staff working at ASTF Baghdad Office is also acknowledged.

\section{REFERENCES}

1. A. Alinsafi, M. Khemis, M.N. Pons, J.P. Leclerc, A. Yaacoubi, A. Benhammou and A. Nejmeddine, Chem. Eng. Process.: Process Intensif., 44, 461 (2005).

2. N. Daneshava, A. Oladegaragoze and N. Djafarzadeh, J. Hazard Mater, 129, 116 (2005).

3. L. Pereira, S.T. Oweis and A. Zairi, Agric. Water Manage., 57, 175 (2002).

4. P. Najafi, S.H. Tabatabaei and K. Asgari, Afr. J. Agric. Res., 5, 1250 (2010).

5. T. Asano and A.D. Levine, Water Sci. Technol., 33, 1 (1996).

6. UN, Water for People, Water for Life-UN World Water Development Report (WWDR), UNESCO and Berghahn Books (2003).

7. Yann Arthus, Making the most of water scarcity: Accountability for better Water Management Results in the Middle East and North Africa, World Bank,Washington, D.C., USA (2007).

8. I. Saif and F. Choucair, Arab Water Council, Arab Countries, Regional Report, Final Draft as of February 24 (2009).

9. F. Hussein and T. Abbas, Int. J. Chem. Sci., 8, 1353 (2010).

10. F. Hussein and T. Abbas, Int. J. Chem. Sci., 8, 1409 (2010).

11. C. Sahunin, J. Kaewboran and M. Hunsom, Sci. Asia, 32, 181 (2006). 
12. S. Eswaramoorthi, K. Dhanapal and D.S. Chauhan, Environ. Technol. Awareness Series, 1, 1 (2008).

13. F.S. Mehmet and Z.S. Hasan, J. Chem. Technol. Biotechnol., 77, 842 (2002).

14. I.A. Arslan, A.B. Isil and W.B. Detlef, Water Res., 36, 1143 (2002).

15. A. Bes-Piá, J.A. Mendoza-Roca, L. Roig-Alcover, A. Iborra-Clar, M.I Iborra-Clar and M.I. Alcaina-Miranda, Desalination, 157, 81 (2003).

16. A. Aleboyeh, Y. Moussa and H. Aleboyeh, Dyes Pigments, 66, 129 (2005).

17. G. Tchobanoglous, F.L. Burton, Franklin, H.D. Stensel, Metcalf and Eddy, Wastewater Engineering: Treatment and Reuse, McGraw- Hill, New York, edn. 4 (2003)

18. S.S. Kalra, S. Mohan, A. Sinha and G. Singh, Advanced Oxidation Processes for Treatment of Textile and Dye Wastewater: A Review, 2nd International Conference on Environmental Science and Development IPCBEE, Vol. 4 (2011).

19. Q. Mahmood, P. Zheng, E. Islam, Y. Hayat, M.J. Hassan, G. Jilani and R.C. Jin, Caspian J. Environ. Sci., 3, 83 (2005)

20. O. Carp, C.L. Huisman and A. Reller, J. Progr. Solid State Chem., 32, 33 (2004).

21. Z. Ambrus, K. Mogyorosi, A. Szalai, T. Alapi, K. Demeter, A. Dombi and P. Sipos, Appl. Catal. A, 340, 153 (2008).

22. N. Takeda, T. Torimoto, S. Sampath, S. Kuwabata and H. Yoneyama, J.
Phys. Chem., 99, 9986 (1995).

23. B. Gao, C. Peng, G.Z. Chen and G. Li Puma, Appl. Catal. B, 85, 17 (2008).

24. M. Tasbihi, C. Rohaidangah, N. Aziz, A. Mansor, A.Z. Abdullah, L.K. Teong and A.R. Mohamed, Ind. Eng. Chem. Res., 46, 9006 (2007).

25. O.M. Alfano, D. Bahnemann, A.E. Cassano, R. Dillert and R. Goslich, Catal. Today, 58, 199 (2000).

26. M. Toyoda, Y. Nanbu, Y. Nakazawa,M. Hirano and M. Inagaki, Appl. Catal. B, 49, 227 (2004).

27. M. Inagaki, R. Nonaka, B. Tryba and A.W. Morawski, Chemosphere, 64, 437 (2006).

28. F. Hussein and T. Abbas, Int. J. Chem. Sci., 8, 1353 (2010).

29. S.B. Sakthivel, M.V. Neppolian, B. Shankar, M. Arabindoo, V. Palanichamy and V. Murugesan, J. Sol. Energy Mater. Sol. Cells, 77, 65 (2003).

30. F. Hussein, A. Alkhateeb and J. Ismail, Electron. J. Chem., 5, 243 (2008).

31. A. Akyol, H. Yatmaz and M. Bayramoglu, Appl. Catal. B, 54, 19 (2004).

32. T. Robinson, G. McMullan, R. Merchant and P. Nigam, J. Bioresour. Technol., 77, 247 (2001).

33. B. Manu and S. Chaudhari, Bioresour. Technol., 82, 225 (2002). 